\title{
Deafness and prolonged neuromuscular blockade following single-dose peritoneal neomycin irrigation
}

\author{
Timothy B. Gilbert MD, \\ Stephen C. Jacobs $M D,{ }^{*}$ \\ Amer A. Quaddoura MD
}

\begin{abstract}
Purpose: A case of deafness is reported in a patient undergoing bilateral nephrectomy after single irrigation of the peritoneal cavity with a neomycin containing solution for surgical prophylaxis.

Clinical Features: In this patient, profound, late-postoperative deafness was heralded by prolonged neuromuscular blockade and respiratory insufficiency. Additional risk factors for ototoxicity in this particular patient included the presence of end-stage renal disease requiring daily peritoneal dialysis and, possibly, the concomitant use of clonazepam and clindamycin.

Conclusions: Antibiotic irrigation solutions containing neomycin may produce unwanted adverse systemic effects of deafness and prolonged neuromuscular blockade, even with only brief application within the peritoneal cavity. Concurrent end-stage renal disease, visceral inflammation from chronic dialysis and laparotomy, and the concomitant use of other medications may have contributed to these unwanted effects.
\end{abstract}

Objectif : Un cas de surdité est rapporté chez un patient subissant une néphrectomie bilatérale après liirrigation simple de la cavité péritonéale avec une solution contenant de la néomycine pour la prophylaxie chirurgicale.

Aspects cliniques : Chez ce patient, une surdité profonde tardive post opératoire a été signalée après l'apparition d'un blocage neuromusculaire prolongé et d'une insuffisance respiratoire. Parmi les facteurs de risque additionnels d'autotoxicité chez ce patient, notons la présence d'une insuffisance rénale terminale exigeant une dialyse péritonéale quotidienne et, peut-être, l'emploi concomitant de clonazépam et de clindamycine.

Conclusion : Les solutions d'irrigation antibiotique contenant de la néomycine peuvent produire des effets généraux défavorables non voulus de surdité et de blocage neuromusculaire prolongé, même avec seulement une brève application dans la cavité péritonéale. L'insuffisance rénale terminale concomitante, l'inflammation viscérale causée par la dialyse péritonéale chronique et la laparotomie, et l'usage concomitant d'autres médicaments peuvent avoir contribué à provoquer ces effets indésirables.

From the Departments of Anesthesiology \& Surgery, ${ }^{\star}$ University of Maryland School of Medicine, Baltimore, MD, USA.

Address correspondence to: Timothy B. Gilbert MD FACC, Director, Division of Cardiothoracic Ancsthesiology, Room S11-Cl0; 22

South Greene Street, Baltimore, MD 21201-1595 USA. Phone: 410-328-6120; Fax: 410-328-5531; E-mail: tgilbert@ancsth.ab.umd.cdu Accepted for publication February 26, 1998. 
$\mathrm{F}$ OLLOWING discovery of neomycin sulfate by Waksman and Lechevalier (1949), ${ }^{1}$ parenteral use of this broad-spectrum antibiotic resulted in reports of nephrotoxicity ${ }^{2}$ and ototoxicity. ${ }^{3}$ Neomycin - like other aminoglycosides-also enhances the effect of neuromuscular blockers, and may result in unwanted and prolonged paralysis. ${ }^{4}$ Modern therapeutic use of neomycin is restricted to oral and topical applications or as a surgical irrigant. Despite minimal absorption across intact tissues, substantial serum concentrations of neomycin can be achieved if given for prolonged periods orally or as an irrigating solution in the setting of active inflammation and/or renal dysfunction. ${ }^{5}$ We report a case of profound deafness occurring after a single irrigation of the peritoneal cavity with neomycin in a patient undergoing bilateral nephrectomy, which was heralded by prolonged postoperative neuromuscular blockade and respiratory insufficiency.

\section{Case Report}

A $48 \mathrm{yr}, 63 \mathrm{~kg}$ woman presented for bilateral removal of massively-enlarged, polycystic kidneys. She had a past medical history of mild asthma, depression, and end-stage renal disease requiring daily peritoneal dialysis (PD). Medication in hospital admission included sertraline, clonazepam and omeprazole. Physical examination showed only a protuberant abdomen with palpable bilateral flank masses and an indwelling PD catheter. No gross impairment of hearing was apparent preoperatively.

Following placement of a lumbar epidural catheter, general anaesthesia was induced with $125 \mathrm{mg}$ thiopentone, $0.5 \mu \mathrm{g} \cdot \mathrm{kg} \cdot \mathrm{min}^{-1}$ remifentanil and $10 \mathrm{mg}$ vecuronium iv. Maintenance consisted of 0.125-0.25 $\mu \mathrm{g} \cdot \mathrm{kg} \cdot \mathrm{min}^{-1}$ remifentanil $i v$ with an inhaled mixture of oxygen, nitrous oxide and isoflurane $(30 \%, 70 \%$, and $0.4 \%$, respectively). As the patient was allergic to penicillins, $900 \mathrm{mg}$ clindamycin iv was given for surgical prophylaxis. The patient was positioned supine for a midline abdominal approach. Two hours after commencement of the surgical procedure, neuromuscular function recovered as evidenced by train-of-four stimulation of the ulnar nerve without fade. One additional dose of vecuronium $(3 \mathrm{mg})$ was given at the request of the surgeon to facilitate retractor adjustment, with complete recovery of the train-of-four after $90 \mathrm{~min}$. Prior to closure of the abdomen, the peritoneal cavity was irrigated with four litres neomycin $0.1 \%$ in warmed normal saline, with near-total recovery of irrigant via suctioning. At the completion of the procedure, all anaesthetics were discontinued and reversal of neuromuscular blockade was attempted with $5 \mathrm{mg}$ neostig- mine and $1 \mathrm{mg}$ glycopyrrolate $i v$. Partial recovery of neuromuscular function was noted over the next ten minutes, with hypopnea and absence of peripheral muscle activity. Repeat neuromuscular assessment revealed no appreciable twitches in a train-of-four, or any response to tetanic stimulation. Consequently, the patient was re-sedated and transferred to the ICU for postoperative ventilation and monitoring. Dense neuromuscular blockade persisted for approximately the next $12 \mathrm{hr}$, after which adequate spontaneous respiration returned and afforded extubation. Although the patient was normocalcaemic pre- and intra-operatively, her serum calcium decreased to $1.62 \mathrm{mmol} \cdot \mathrm{l}^{-1}$ on the first postoperative day. Because of the extensive laparotomy, alternative day hemodialysis was substituted in place of routine PD during the subsequent month.

The patient began to notice decreased hearing about postoperative day six, but did not relate any auditory complaints to the surgical team. During outpatient follow-up on postoperative day eight, moderately profound bilateral deafness was noted by the examining physician. "Helicopter-like" tinnitus was reported by the patient, which only partly diminished over the ensuing weeks. Detailed audiometric testing three weeks postoperatively revealed bilateral severe-to-profound sensorineural hearing loss, particularly in higher frequencies. Speech awareness thresholds were in agreement with the pure-tone averages, as she exhibited $0 \%$ word discrimination at the maximum audiometer output into each ear. Tympanometry revealed normal eardrum mobility, but acoustic reflexes were absent for each ear during ipsi- and contra-lateral stimulation. Audiologic and otolaryngologic consultants confirmed that the acute bilateral hearing loss was consistent with chemical ototoxicity. Because of the communicatively significant hearing impairment, the patient was given a trial of biaural amplification and speech reading instruction. She remains under evaluation for cochlear implantation at a later date, if no substantial improvement in acuity occurs.

\section{Discussion}

The adverse effects of aminoglycoside antibiotics have been well described, including toxic effects to the kidneys and ears, and synergism with drugs that affect neuromuscular transmission. Neomycin -one of the oldest aminoglycosides still available-has found extensive use as an irrigant of wounds and body cavities, owing to its broadspectrum coverage, limited absorption (as a highly-polar cation) and low cost. Previous reports have focused primarily on adverse effects that occurred after prolonged (i.e., usually days to weeks) use or inadvertent overdosage, often in the serting of preexisting renal dysfunction. 
In the patient described here, a single dose of temporarily-instilled intraperitoneal neomycin $(\sim 4 \mathrm{~g})$ resulted in prolonged neuromuscular blockade and profound, late-postoperative deafness. Although other causes of acute deafness cannot be excluded-such as viral or autoimmune labyrinthitis-the temporal relationships between the surgical procedure, prolonged paralysis and hearing loss implicate use of neomycin. Early, high-pitched tinnitus, followed by loss of high frequency perception, and ultimately lower frequencies is commonly observed in aminoglycoside ototoxicity. ${ }^{6}$ Neomycin is particularly toxic to the cochlear apparatus, ascribed to dose-dependent accumulation of drug within inner ear fluid. Although the bacteriocidal serum neomycin concentration is $5-10 \mu \mathrm{g} \cdot \mathrm{ml}^{-1}$, ototoxicity has been reported at substantially lower levels of 0.4-1.2 $\mu \mathrm{g} \cdot \mathrm{l}^{-1}$ in patients with no predisposing factors. ${ }^{7}$ Due to limited availability of obtaining neomycin levels (requiring off-site processing), and that the patient was discharged before the diagnosis of acute hearing loss, laboratory confirmation of a persistent serum neomycin concentration was not possible.

Reasons why this patient was particularly susceptible to brief exposure of neomycin are several. The effect of chronic PD usually results in some degree of peritoneal inflammation from the daily instillation of hyperosmolar dialysates, which may have afforded greater systemic uptake of the antibiotic. Indeed, preferential unidirectional (inward) absorption of intraperitoneal aminoglycosides has been noted in PD patients. ${ }^{8}$ End-stage renal disease eliminated the major pathway for excretion, as neomycin is almost entirely renally-excreted. However, since aminoglycosides are removed from the body by haemodialysis (with $-50 \%$ of an administered dose removed over 12 hrs of therapy), ${ }^{6}$ any residual neomycin should have been extracted during the initial postoperative days.

A number of potential drug interactions exist that could have potentiated the extant neuromuscular blockade. Clindamycin-a non-aminoglycoside, lincosamide antibiotic - can produce neuromuscular block by a combination of pre- and post-junctional actions, as well as reducing muscle contraction directly. ${ }^{9}$ Clonazepam, like most benzodiazepines, can weakly enhance binding of GABA receptors not only in the brain, but also in the peripheral nervous tissue. ${ }^{10}$

Prolonged neuromuscular blockade from aminoglycoside interaction is usually only partly responsive to routine anticholinesterase reversal agents, as demonstrated here. However, the response to calcium is generally good, particularly if hypocalcaemia is detected. ${ }^{4,6,9}$ As the diagnosis of neomycin-induced blockade was made retrospectively, and the patient was normocalcaemic intraoperatively, the response to calcium was not determined in this patient.

Although the prolonged neuromuscular blockade universally reverses with time, the deafness is usually permanent. Therefore, we concur with other authors ${ }^{2-7}$ who have suggested that careful consideration of the risks and benefits of the use of instilled neomycin should be undertaken, particularly in the patient with end-stage renal disease and peritoneal dialysis.

\section{Acknowledgment}

The authors acknowledge the assistance of Heidi Louie, pharm. D. for providing references and reviewing this article.

\section{References}

1 Waksman SH, Lechevalier $H A$. Neomycin, a new antibiotic active against streptomycin-resistant bacteria, including tuberculosis organisms. Science 1949; 109: 305-7.

2 Powell $L W J$ J, Hooker JW. Neomycin nephropathy. J Amer Med Assoc 1956; 160: 557-60.

3 Greenwood GJ. Neomycin ototoxicity. Report of a case. Arch Otolaryngol 1959; 69: 390-7.

4 Coleman JW, Artusio JF, Yao FY, McGovern JH, Jalandoni SR. Neomycin-induced neuromuscular blockade. Urology 1981; 17: 265-7.

5 Davia JE, Siemsen AW, Anderson RW. Uremia, deafness, and paralysis due to irrigating antibiotic solutions. Arch Intern Med 1970; 125: 135-9.

6 Sande MA, Mandell GL. Antimicrobial agents. The aminoglycosides. In: Gilman AG, Goodman LS, Gilman A (Eds.). The Pharmacological Basis of Therapeutics, 6th ed. New York: MacMillan Publishing Company, Inc., 1980: 1162-80.

7 de Oliveira JAA. Audiovestibular Toxicity of Drugs, Vol 1. Boca Raton: CRC Press Inc., 1989: 234-5.

8 Somani P, Shapiro RS, Stockard H, Higgins JT. Unidirectional absorption of gentamicin from the peritoneum during continuous ambulatory peritoneal dialysis. Clin Pharmacol Ther 1982; 32: 113-21.

9 Singh XN, Marshall IG, Harvey AL. Pre- and postjunctional blocking effects of aminoglycoside, polymyxin, tetracycline and lincosamide antibiotics. $\mathrm{Br} \mathrm{J}$ Anaesth 1982; 54: 1295-306.

10 Silverman DG, Mirakbur $R K$. Effects of other agents on nondepolarizing relaxants. In: Silverman DG (Ed.). Neuromuscular Block in Perioperative and Intensive Care. Philadelphia: J.B. Lippincott Company, 1994: 104-22. 